\title{
Da salvação pela fé à cura pela autoestima: as origens religiosas do testemunho de vítima ${ }^{1}$
}

\author{
Paulo Vaz' \\ https://orcid.org/0000-0002-8776-2715 \\ Nicole Sanchotene ${ }^{1}$ \\ https://orcid.org/0000-0001-8254-6530
}

\author{
Amanda Santos' \\ https://orcid.org/0000-0001-9401-163X \\ I - Universidade Federal do Rio de Janeiro. \\ Rio de Janeiro (RJ). Brasil.
}

Resumo: Nas últimas décadas, observou-se uma explosão do gênero testemunhal nos meios de comunicação ao redor do mundo e sua centralidade para as políticas de identidade contemporâneas. Este artigo propõe que a origem destes testemunhos de vítimas de preconceito, que mesclam terapia e política, remonta às práticas protestantes, especialmente no interior da cultura norte-americana. O percurso genealógico proposto começa nas narrativas de conversão do século XVI, passando pela expansão do Metodismo nos Estados Unidos até o surgimento dos grupos de autoajuda laicos no século $X X$, marcados pela ideia de pensamento positivo e, mais tarde, de autoestima. Assim como Foucault propôs a confissão clínica como secularização da confissão católica, propomos que os testemunhos de vítima podem ser a secularização das narrativas de conversão. 
Palavras-Chave: testemunho; vítimas de preconceito; genealogia; conversão religiosa; protestantismo norte-americano; secularização.

\begin{abstract}
From salvation by faith to healing by self-esteem: the religious origins of victim testimony - In recent decades, we have witnessed an explosion of the testimonial genre in the media worldwide, as well as its centrality to contemporary identity politics. This article proposes that the origin of victim testimonies, which mix therapy and politics, dates back to Protestant practices, especially within the North-American culture. The proposed genealogical path begins in the 16th-century conversion narratives, going through the expansion of Methodism in the United States until the emergence of secular self-help groups in the 20th century, marked by the idea of positive thinking and, later, self-esteem. Just as Foucault proposed clinical confession as secularization of Catholic confession, we propose that victim testimonies might be the secularization of conversion narratives.
\end{abstract}

Keywords: testimony; victims of prejudice; genealogy; religious conversion; north-american protestantism; secularization.

\title{
Cenas de testemunho
}

"Como curei minha compulsão alimentar", "10 coisas que só usei depois de me aceitar", "Racismo na Medicina: minha história e experiências", "Na minha pele", "Tudo sobre próteses e minha amputação", "Minha vida com colostomia", "Depressão e Suicídio - Meu Testemunho", "Vivendo com câncer: histórias de superação", "Aborto espontâneo - Minha história de perda gestacional e como superar", "Bi: Um desabafo bagunçado porém sincero sobre se descobrir", "A minha história de amor virou um pesadelo", "Morri para Viver: meu submundo de fama, drogas e prostituição", "Como foi ser diagnosticado e como é viver com HIV", "Todo preconceito e bullying que sofri na escola". Esses são alguns títulos retirados de vídeos e livros publicados desde 2015 que dão pistas sobre um aumento súbito de narrativas autobiográficas nos meios de comunicação. Este interesse midiático começou nos anos 80 e passou a ser objeto das ciências humanas desde os anos 90 - por exemplo, Illouz (2003), Mehl (1996), Plummer (1995).

Para além desses conteúdos, percebemos também uma proliferação de movimentos sociais calcados na ideia de testemunho e na denúncia de preconceito nos últimos anos. Podemos citar o movimento It Gets Better como um dos precursores desta tendência. O movimento surgiu em 2010 no YouTube como resposta a uma sequência de suicídios de adolescentes causados por bullying homofóbico nos Estados Unidos. A ideia do projeto era publicar 
vídeos de adultos homossexuais contando suas experiências e passando a mensagem de que as coisas melhorariam para estes jovens no futuro. $O$ projeto foi extremamente bem-sucedido: mil vídeos foram submetidos apenas na primeira semana, ultrapassando o limite da plataforma. Nos meses seguintes, o movimento ganhou repercussão mundial. ${ }^{2}$

Em 2014, alunos da universidade de Harvard iniciaram o movimento I, too, am Harvard, para relatar as experiências de microagressão e preconceito sofridas por alunos de minorias étnicas e raciais da instituição. $O$ projeto foi reproduzido em diversas universidades; no Brasil, foi inspiração para a campanha \#AhBrancoDáUmTempo.

Nestes movimentos, o relato de experiências de indivíduos comuns serviu para mobilizar, formar grupos, gerar identificação e, por vezes, fazer reivindicações políticas. O movimento feminista teve papel central em difundir essa estratégia: no Brasil, presenciamos as campanhas de grande repercussão "Meu Primeiro Assédio" (2015), e "Eu Vivi um Relacionamento Abusivo" (2017). A campanha \#MeToo surgiu na internet com relatos de assédio e agressão sexual que culminaram nas acusações de abuso contra Harvey Weinstein, em 2017, e repercutiu internacionalmente, gerando movimentos similares em mais de 30 países. No Facebook, nas primeiras 24 horas, a hashtag foi usada por mais de 4,7 milhões de usuários em 12 milhões de postagens ${ }^{3}$. Em 2021, o movimento ganhou um novo capítulo com a denúncia de incesto contra Olivier Duhamel, proeminente acadêmico francês. Após a revelação do caso, o coletivo feminista NousToutes lançou a hashtag \#MeToolnceste para incentivar outras vítimas a denunciarem seus agressores. O sucesso desses movimentos inspirou outros grupos e indivíduos que se concebem como vítimas de preconceito a buscar visibilidade e relevância política através do testemunho como forma de mobilização: a lista de causas e movimentos é longa e aberta, pois inclui toda forma de posicionamento de indivíduos em que o sofrimento experimentado pode ser atribuído, ao menos em parte, a algum tipo de preconceito.

A intensa repercussão social e midiática desses movimentos indica a relevância do testemunho na cena política contemporânea e abre uma questão histórica: esses testemunhos se originaram de que práticas discursivas anteriores? 
No Brasil, a origem comumente proposta articula as vítimas de preconceito com os relatos de vítimas do Holocausto, do governo racista na África do Sul e das ditaduras latino-americanas (BEVERLEY, 2008; CARUTH, 1991; AGAMBEN, 1999; SELIGMANN-SILVA, 2008). Nos casos dessas análises, a cena privilegiada é o tribunal: por exemplo, o julgamento de Eichmann em 1961; o trabalho da CONADEP (Comissão Nacional sobre o Desaparecimento de Pessoas) que resultou no Julgamento das Juntas em 1985, na Argentina; e a formação da Comissão da Verdade e Reconciliação (1996) para examinar os atos cometidos contra os direitos humanos durante o Apartheid.

Na cena do tribunal, tal como proposto por esses estudos, as narrativas de sofrimento individual revelam os horrores causados pelo Estado totalitário. Por partirem das experiências do Holocausto e das vítimas de ditadura, assumem que o testemunho surge apenas na segunda metade do século XX atribuindo de antemão um valor de "heroísmo", de resistência, para essas narrativas. No entanto, os testemunhos que circulam nos meios de comunicação parecem mesclar terapia e política.

Para estudar a origem destes testemunhos contemporâneos, a cena do tribunal precisa ser complementada por cenas de salvação e participação política. A verdade dos testemunhos permite julgar, curar e mobilizar. Assim, é preciso incluir a história da religião cristã e pensar nas suas formas de redimir individual e coletivamente pelo discurso.

A questão fundamental nos testemunhos de vítima de violência do Estado é saber como um evento extraordinário, que provoca experiências de sofrimento inauditas, pode ter sido silenciado ou ser indizível, embora funde, em cada um que sobreviveu, a obrigação de narrar (AGAMBEN, 1999). Nos testemunhos de vítimas de preconceito, a questão pertinente passa a ser a de saber como e por que os indivíduos falam de suas vidas privadas no espaço público. Que conjunto atual de crenças e valores e que conjunto prévio de práticas discursivas tornaram possível que indivíduos superassem a reserva antes habitual em relação ao sofrimento e à sexualidade e se dispusessem a contar para um indivíduo qualquer (e não ao padre ou ao terapeuta) suas experiências? ${ }^{4}$

\footnotetext{
4 A forma usual de relacionar o pensamento de Foucault às narrativas testemunhais de vítimas é pelo conceito de parrhesia, com a coragem de falar a verdade ao poder sendo o ponto crucial. Propomos aqui uma perspectiva distinta: primeiro, pensando o testemunho na sua diferença com a confissão; segundo, partindo da questão crítica do destacamento da verdade; por fim, pela necessidade de pensar historicamente de onde surgiu essa narrativa autobiográfica, se ela pode ser a secularização de práticas espirituais norte-americanas.
} 
O que se pretende é propor uma história distinta de como os indivíduos passam a ir ao espaço público para narrar suas experiências de sofrimento, sugerindo que os testemunhos possuem uma origem mais remota, associada às autobiografias protestantes que datam do século XVI.

\section{Por uma outra história do testemunho}

Uma vez que quatro séculos separam o testemunho contemporâneo da origem que estamos indicando, cabe apenas determinar eventos históricos que puderam dar lugar aos elementos estruturais dessa prática. Para dar início a uma genealogia, é preciso ter clareza conceitual quanto à prática que se deseja historicizar: clareza em relação ao objeto, mas também em relação a história de seu surgimento, uma história que não supõe que o fim está na origem, ou seja, que as práticas do presente estavam lá desde o início, mas que existem apropriações e deslocamentos de sentido (FOUCAULT, 1979). Além disso, clareza sobre as condições do presente que suscitam a historicização (aquilo que chamamos de multiplicação das narrativas testemunhais). Em relação ao conteúdo, o testemunho de vítima de preconceito é uma narrativa autobiográfica orientada por uma certa relação com as regras morais. Pelo senso comum, autobiografia narra as experiências de um indivíduo; mas o que é experiência?

O conceito de experiência proposto por Foucault em $O$ uso dos prazeres (1984) sustenta e permite pensar esse nexo entre autobiografia e regras morais. Experiência é "a correlação, em uma cultura, entre campos de saber, tipos de normatividade e formas de subjetividade" (1984, p. 10). É a partir da separação entre discursos verdadeiros e discursos falsos sobre os seres humanos que um indivíduo pensa o que lhe acontece e o que ele faz, distinguindo então, na sua conduta e na dos outros, o que é certo do que é errado, o que é pecado do que respeita à Deus, o que é normal do que é patológico. A partir dessa distinção moral, o indivíduo é capaz então de atribuir sentido e valor à sua conduta, isto é, às suas ações, pensamentos e desejos.

A narrativa de acontecimentos e ações, assim como da contrapartida psíquica que eles suscitam, é estruturada pelo que se tem por verdadeiro e pelo horizonte limitado de regras morais tornadas possíveis por essas verdades historicamente situadas. A relação com as regras morais, por ser também uma relação com a verdade, proporciona diferentes orientações autobiográficas. $\mathrm{O}$ conteúdo pode estar centrado nos esforços de se adequar 
a regras morais excessivamente exigentes; os inúmeros fracassos e a verdadeira constrição se tornam parte essencial do relato. A narrativa autobiográfica também pode focar na necessidade de descobrir o que se deseja para além do que se é autorizado a desejar, requisição que orienta o indivíduo a estabelecer uma distância com as regras morais de sua cultura. A narrativa também pode acentuar a necessidade de questionar as imposições morais dos outros dos quais se depende epistêmica e afetivamente. Em todos esses discursos, concebemos nosso ser, nossas histórias singulares, a partir dos jogos de verdade, isto é, a partir desses “jogos entre o verdadeiro e o falso, através dos quais o ser se constitui historicamente como experiência, isto é, como podendo e devendo ser pensado" (FOUCAULT, 1984, p. 13).

Judith Butler, provavelmente inspirada nessa concepção de experiência, também propõe que

[...] os termos usados para darmos um relato de nós mesmos, para nos fazer inteligíveis para nós e para os outros, não são criados por nós: eles têm caráter social e estabelecem normas sociais, um domínio de falta de liberdade e de substituibilidade em que nossas histórias 'singulares' são contadas (BUTLER, 2015, p. 17).

Analisemos então o testemunho de vítima de preconceito: num primeiro sentido, imediato, um testemunho narra a luta de um indivíduo para se libertar das regras morais de sua cultura que lhe restringem. O conteúdo de cada narrativa pode ser diferente dependendo da figura escolhida para incorporar o preconceito limitador e violento. No sentido reflexivo, porém, os testemunhos contêm ao menos duas características idênticas. Primeiro, eles narram as peripécias sofridas por cada indivíduo em sua luta para resistir à presumida pressão de conformidade proposta pela sociedade — presumida porque a pressão social parece ser a de ser autêntico, o que se extrai da própria identidade estrutural das narrativas. Em segundo lugar, são narrativas que explicam o sofrimento por atribuição de responsabilidade ao outro.

Ainda segundo o conteúdo, esses testemunhos de vítimas de preconceito são uma forma de autoexposição do sofrimento contingente no espaço público. Contingente porque atribuem responsabilidade humana, assumindo que o sofrimento poderia não ter acontecido se as ações imorais do outro tivessem sido coibidas ou desestimuladas. Já houve na história do ocidente um outro modo de articular a existência de sofrimento à imoralidade, a confissão. Mas esta implicava a imoralidade do narrador como causa. É preciso, 
portanto, se colocar a questão: já houve outro modo de articular sofrimento e moralidade?

Quando se pensa o testemunho de vítimas na sua dimensão terapêutica, a comparação, de fato, é com a confissão católica e seu dispositivo secular, a psicanálise (FOUCAULT, 1988). Três diferenças se destacam: causa do sofrimento, publicidade e horizontalidade. A primeira, como dito acima, é uma diferença no nexo entre sofrimento e responsabilidade. Na confissão católica, o alívio espiritual e a salvação ocorriam quando o indivíduo era capaz de dizer "sofro por minha culpa". Na psicanálise, o indivíduo deveria mudar sua relação com as regras morais que tanto limitavam sua capacidade de desejar; desse modo, tinha que aprender a dizer: "sofro porque acredito na culpa". No testemunho contemporâneo, por ser o discurso de uma vítima, o indivíduo passa a dizer "sofro por culpa do outro". Essa diferença, construída em relação à responsabilidade, pode ser descrita como a passagem de narrativas que tinham por objeto o desejo para uma narrativa cujo objeto é a violência.

As outras duas diferenças são de forma da prática discursiva. Primeiro, o testemunho se dá no espaço público e não no segredo do confessionário ou do divã. Decorre daí a terceira diferença, a de interlocutor, que no testemunho passa a implicar uma relação de igualdade entre quem fala e quem escuta. Antes, o indivíduo narrava sua vida ao padre ou ao psicanalista, isto é, a alguém capaz de estabelecer a sua verdade, um perito no autoengano, capaz de desvelar para o sujeito o que ele não sabia desejar. No testemunho, porém, o indivíduo fala para um interlocutor semelhante sobre suas experiências, com quem se supõe não haver relação hierárquica, sem abrir espaço para questionamento de sua versão.

Essa horizontalidade pressuposta pelo testemunho como prática discursiva implica, portanto, uma mudança no lugar da verdade. Antes, a verdade era estabelecida por quem julgava ou interpretava o relato. Agora, ela reside na autoridade da experiência do sofredor/sobrevivente, que surge como aquele que sabe porque viveu. Dada a relevância da autoridade da experiência, a representação do sofrimento não deve ser feita nem questionada pelo olhar externo. É preciso destacar na história, portanto, as condições para esse novo lugar do verdadeiro, com o consequente privilégio de narrar a sua vida privada para indivíduos quaisquer. Essa questão conduz a uma outra: como foi possível surgir na história uma prática terapêutica da forma muitosmuitos, diferente da forma um-um característica da confissão e da análise? 
A forma dessa prática discursiva tem mais um elemento: sobre quem o discurso produz efeito. Imediatamente, produz efeitos terapêuticos sobre quem fala; mas também produz efeitos em quem escuta ou lê. Os testemunhos de vítima são um relato de si que pretende transformar outras potenciais vítimas, convidando então a audiência a se identificar com a experiência relatada e a se mobilizar para reduzir as chances de que eventos semelhantes aconteçam. É preciso pensar, portanto, que eventos históricos permitiram a narrativa da vida privada se tornar um fator de mobilização política.

A comparação com a forma imediatamente anterior de mobilizações políticas organizadas por partidos e os movimentos sindical e estudantil modernos sugere a investigação histórica. Na formulação usada pela teoria da comunicação, a forma era a relação um-muitos, onde líderes discursavam para mobilizar uma audiência relativamente passiva. Três características imediatas permitem diferenciar o testemunho dessa política moderna: a relevância de se falar sobre a vida privada para a conscientização e mobilização, quando antes não se dava importância; a própria forma de mobilizar, que requer que outros indivíduos saiam da posição de meros receptores e passem a também narrar sua vida privada; por fim, a maior horizontalidade entre quem fala e quem escuta. O testemunho de vítimas supõe, como vimos, a forma muitos-muitos também na prática política.

Historicizar essas diferenças significa atentar para as origens religiosas das práticas. A diferença de origem no caso da prática terapêutica é mais direta. Foucault argumentou que a psicanálise é a secularização da confissão católica (FOUCAULT, 2014); já os grupos de autoajuda devem ser considerados como a secularização das narrativas de conversão protestantes. Talvez um argumento semelhante possa ser feito sobre a forma de ordenar uma coletividade pelo discurso. A missa católica é hierárquica e diferente da forma de ordenação coletiva pelo discurso feita por algumas denominações protestantes; sobretudo, diferente dos pequenos grupos de testemunho da graça, tão relevantes para a religiosidade norte-americana (WUTHNOW, 1994).

\section{Verdade da fé, verdade do sujeito}

A genealogia do sujeito de desejo foi formulada por Foucault a partir das técnicas de confissão católicas: de um lado, pensou suas condições de possibilidade na diferenciação das práticas de estética da existência na cultura greco-romana; de outro, descreve a longa história da transformação 
dessas práticas na cultura cristã até a sua secularização na forma da psicanálise no final do século XIX. Uma análise de sua obra mostra que Foucault não considerou a Reforma Protestante nessa genealogia, a não ser como provocadora da Contrarreforma. No Dits et écrits (1994), a Reforma Protestante não aparece no índice remissivo; Calvino e Lutero não constam no índice onomástico. Só há uma breve referência a John Wesley, que se centra nas técnicas de punição e não nas narrativas autobiográficas de conversão (FOUCAULT, 1994, p. 596-597).

Nos dois livros escritos nos anos 1970 em que Foucault trata da confissão - A vontade de saber (1988) e Os anormais (2001) -, a Reforma é mencionada ora por ter gerado a Contrarreforma e as mudanças que esta provoca nas técnicas de confissão, ora para subentender que seu estudo não traria muita novidade, pois as pastorais do sexo católica e protestante se pareceriam (FOUCAULT, 1988, p. 150, nota 4). Já no início dos anos 1980, Foucault passa a marcar uma diferença crucial entre catolicismo e protestantismo: o primeiro separa a obrigação de acreditar da obrigação de descobrir dentro de si sua verdade recôndita, a hermenêutica do livro e a hermenêutica de si, enquanto o segundo reúne as duas, mas de modo a que a verdade que se descobre dentro de si é a verdade que está na Bíblia: acreditar em Jesus Cristo Salvador (FOUCAULT, 2014, p. 92-93).

Assim, Foucault não desenvolveu uma análise nem dos movimentos espirituais e políticos decorrentes da Reforma, nem do sujeito produzido por esta ruptura. O esforço da genealogia que propomos é, portanto, observar o que seria uma subjetividade desenvolvida a partir das práticas de salvação protestantes, e quais as suas diferenças para o sujeito de desejo produzido pelas práticas de confissão.

Como apontado, o protestantismo reúne a verdade da fé e a verdade do sujeito em uma só, na hierarquia clara da primeira sobre a segunda. A inovação maior de Lutero teria sido afirmar que basta a fé para a salvação, o que retira a importância do trabalho de si sobre si para se constituir como sujeito moral (FOUCAULT, 2014, p. 174). A primeira dimensão da salvação pela fé é, portanto, o modo como o indivíduo pensa sobre si mesmo. Por ser condição necessária e suficiente para a salvação, a fé não é apenas crença em Deus e em Jesus Cristo Salvador, não é apenas crença sobre o que é o mundo e o que nele existe; a fé é também, e imediatamente, uma atribuição de sentido e valor a si mesmo. Por ter fé, o indivíduo pertence aos eleitos. 
De um ponto de vista secular, isso significa que o indivíduo, ao ter fé, também passa a pensar bem de si mesmo. Um anacronismo sugere a dependência histórica: ter fé implica ter alta autoestima.

Já no catolicismo, por sua dupla obrigação de verdade, acreditar em Deus não implica que o cristão pense bem sobre si; ao contrário, por implicar a descoberta de sua natureza pecaminosa, a fé o incita a lutar contra si, contra suas tentações, através do esforço reflexivo de saber o que determina seu comportamento, reflexividade que tem como condição dizer a sua verdade ao pastor. Para o católico, não basta a verdade da fé para a salvação: faz-se necessário um lento trabalho espiritual de descobrir a verdade de seu desejo, isto é, a salvação dependia essencialmente de uma modificação no comportamento. A confissão era modo de estabelecer um conflito entre dois desejos no interior de cada indivíduo: o desejo pecaminoso e o desejo de Deus, tipicamente sob a forma de amor ao pastor (FOUCAULT, 1988).

Na versão luterana, a salvação pelos atos é impossível, dada a dimensão interior da espiritualidade e a extensão da lei de Deus. Contudo, pela fé em Cristo Salvador, o indivíduo descobre-se desde sempre já salvo. Com o protestantismo, a salvação torna-se condição da "santificação: através da fé, modifica-se a relação consigo, pois ter fé significa que a vontade de Deus passa a dar suporte à vontade do indivíduo, que se torna capaz de melhor controlar os impulsos do seu corpo (DELUMEAU, 2003). Como a fé implica a intercessão da vontade divina na luta da vontade humana contra os impulsos do corpo, o indivíduo que se descobre salvo se singulariza pela força de sua vontade. Em vez de o bom comportamento ser a causa da salvação, como no caso dos católicos, a fé e a salvação seriam responsáveis por causar a modificação no comportamento pecaminoso e explicar, por exemplo, o sucesso material nessa vida. Para aqueles marcados pela religiosidade protestante, quanto mais positivamente o indivíduo pensar sobre si, mais será capaz de se comportar segundo princípios morais - de Deus ou de sua cultura.

As críticas que Lutero endereçou aos dispositivos confessionais de direção e exame de consciência contêm em potência a forma comunicacional dos testemunhos de vítima. Para Lutero, a confissão era uma forma de padres e membros do clero exercerem um poder ilegítimo. Proposta como alternativa à confissão, havia a prática de confessar pecados para a comunidade como forma de ser reconfortado. No protestantismo, portanto, a hierarquia espiritual e a mediação pressupostas pela direção de consciência são abolidas. 
A Igreja Católica requeria a "confissão completa", o esforço de se lembrar de todos os pecados cometidos, e a atenção cada vez maior, especialmente depois do século XVI, dedicada à carne, ao que determina a pecaminosidade dos fiéis e que pode escapar à sua consciência. Na confissão católica, portanto, o trabalho espiritual já se inquietava com a possibilidade do autoengano e buscava meios para reforçar a consciência de si. As denominações protestantes, por sua vez, não enfatizavam o exame de consciência. Cabia confessar a membros da comunidade os pecados que estavam imediatamente na consciência, sem preocupação de completude, sem se inquietar com aqueles que podia ter esquecido, sem se preocupar com alguma determinação inconsciente do comportamento que faz esquecer do essencial e que conduz o indivíduo a continuar a pecar (DELUMEAU, 2003; TENTLER, 1977). Além de não abrir a investigação sobre a determinação inconsciente do comportamento, esse modo de confessar pecados habitua os indivíduos a falar de sua vida privada para outros de mesmo nível hierárquico e supõe que a superação da vergonha é critério de verdade da narrativa.

As críticas à direção e ao exame de consciência parecem implicar a ausência de qualquer forma de trabalho sobre a culpabilidade. Ao mesmo tempo, a Reforma reforça a culpabilidade por acentuar a dimensão espiritual da lei de Deus, ao fato de que podemos nos comportar exteriormente segundo a lei, embora estejamos no pecado na solidão de nossas consciências. Como alguém transtornado pela culpa pode trabalhar pela salvação, a sua e a dos outros, se ela é graça de Deus? Como apaziguar as almas aterrorizadas pela expectativa do inferno?

A resposta consiste em ver a diferença na dimensão temporal do trabalho de livrar-se do fardo da culpa. A confissão católica implica o recorrente deve-se confessar regularmente os pecados por toda a vida - e o progressivo, pois se espera que, ao longo dos anos em que confessou e por ter confessado, o fiel consegue paulatinamente estabelecer outra relação com seus desejos. Já a tradição protestante supõe o evento transformador de identidade, supõe a conversão pela fé.

A questão se torna, então, o que faz com que alguém descubra a fé, com que alguém se converta? Para o desenvolvimento das práticas terapêuticas protestantes, são relevantes dois caminhos, articulados. Um é a leitura da Bíblia: ao invés da relação com o pastor, a relação imediata com o Espírito Santo. E o outro, fundamental para a história do testemunho, é escutar e 
ler relatos autobiográficos de como alguém encontrou a fé. Narrar sua conversão podia fazer com que outros se convertessem; a narrativa promove mudanças espirituais em quem narra e em quem escuta ${ }^{5}$.

\section{A generalização da autobiografia: de 1600 a 1780}

A narrativa de conversão espiritual começa no século XVI com a autobiografia dos grandes líderes espirituais, como Lutero e Calvino. Se a salvação depende da descoberta da fé, o que importa narrar não é o pecado que se cometeu, mas o momento em que a graça tocou a vida de um indivíduo. O que importa não é a narrativa contínua dos esforços de superar o pecado, mas o evento em que a graça se mostrou ao indivíduo e o transformou: evento e identidade, em vez de cuidado reflexivo contínuo para enfrentar o pecado. Nessas narrativas evangélicas, o indivíduo narrava o momento de extrema culpa e desespero por perceber que não poderia jamais deixar de ser um pecador. Lutero escreveu em 1545 um fragmento autobiográfico no qual narrava brevemente o momento em que compreendeu que "embora vivesse como um monge de forma louvável, [...] era um pecador diante de Deus com uma consciência extremamente perturbada.". Mas essa descoberta angustiante foi seguida pela revelação da misericórdia de Deus ao se perceber salvo: "Nesse momento, eu senti que nasci de novo e havia adentrado os portões abertos do paraíso" (HINDMARSH, 2005, p. 25).

Uma estrutura se repete nesses relatos:

1. no início, o conhecimento da religiosidade formal marcado pela exterioridade, onde o que importava para o indivíduo era apenas a obediência aos dogmas e rituais;

2. uma intensa internalização da regra: o indivíduo descobre a extensão da lei de Deus e se torna consciente sobre seus próprios pecados;

3. o absoluto desespero diante da certeza da punição - o momento extremo da culpa;

4. a salvação pela graça divina, o reconhecimento da misericórdia de Deus, a absolvição dos pecados e a profunda alegria espiritual;

5. por fim, uma nova obediência à lei se torna possível porque a vontade do indivíduo é reforçada pela vontade de Deus (HINDMARSH, 2005).

5 Cabe notar que a confissão só redimia quem confessava; a preocupação com os efeitos da confissão sobre quem a escuta se limitava ao temor de incitação ao pecado, de estímulo do desejo diante do narrado. (FOUCAULT, 2001) 
Essa forma autobiográfica vai se difundindo a partir do século XVIII por uma série de regulações e práticas de diferentes denominações. Por exemplo, os puritanos nos Estados Unidos, marcados pelo Calvinismo, se preocupavam com a distância entre a Igreja divina, necessariamente com poucos eleitos, e a Igreja humana, infelizmente numerosa, contendo muitos pecadores. Passaram então a requerer uma narrativa de conversão como teste de admissão (CALDWELL, 1983).

O início do Metodismo estende ainda mais o direito de narrar sua vida e modifica o sentido dessas narrativas. Os metodistas acreditavam na possibilidade de todos serem salvos; assim, uma narrativa de conversão, ao invés de ser evidência de pertencimento ao grupo restrito dos eleitos, era modo de converter novos fiéis e incitá-los a também tomar a palavra, narrar suas experiências de pecado e o evento da graça em suas vidas (HINDMARSH, 2005). A narrativa metodista frisava a importância da descoberta do divino e da fé no indivíduo, ao contrário de outras denominações que davam antecedência ao estudo formal da liturgia. Preocupado em conquistar as classes populares, o Metodismo rejeitou o papel das autoridades religiosas tradicionais, valorizando a experiência da fé interior a cada indivíduo. Ao afirmar que qualquer indivíduo leigo poderia ter certeza de sua salvação e, portanto, pregar a palavra de Deus para outros convertidos, ocasionou um gigantesco aumento no número de narrativas de conversão, que se tornou a prática mais importante de sua cultura religiosa (HINDMARSH, 2005, p. 156). Aproximamo-nos do testemunho contemporâneo: em termos seculares, o relato autobiográfico transforma o que seus ouvintes/leitores pensam sobre si mesmos e os mobiliza a também narrarem suas vidas.

O procedimento metodista de conversão é levado aos Estados Unidos e se transforma no século XIX nas ondas de renovação religiosa conhecidas como Revivals, encontros de dias em que pessoas escutavam sermões e narrativas autobiográficas, convertendo-se em massa a uma denominação e, uma vez mais, onde muitos tomavam a palavra para narrar suas vidas (MCLOUGHLIN, 1978). Os revivals representaram “um novo episódio na história da autobiografia espiritual que se iniciou no final da década de 1730 [...] Nesse contexto, narrativas de conversão feitas por homens e mulheres, líderes e leigos, publicadas ou não, começaram a se multiplicar" (HINDMARSH, 2005, p. 61).

\section{Secularização e Modernidade: de 1800 a 1960}

Embora os revivals tenham expandido a prática do testemunho de fé no espaço público, eles não tinham dimensão política, pois visavam apenas 
à salvação individual. A transformação coletiva com fins seculares pode ser recuada às mobilizações de presbiterianos e evangélicos pela temperança e contra a escravidão, ambas nos anos 30 do século XIX (YOUNG, 2002). Partindo da crença no excepcionalismo norte-americano, de que Deus teria celebrado uma nova aliança, agora com seus habitantes, esses movimentos supunham que os pecados individuais causavam males sociais: ameaçavam atrair a cólera divina e o rompimento da aliança. Desse modo, partiam em busca da conversão dos pecadores, baseando-se na experiência evangélica do despertar.

Esses protestos de caráter nacional configuram um segundo momento deste processo de democratização e secularização do testemunho. Neles, homens e mulheres se reuniam para testemunhar contra os pecados da embriaguez e da escravidão. Podia ocorrer de um pecador se converter em público, o que incentivava a conversão de outros. No caso da temperança, um bebedor, talvez ainda bêbado, ao assistir uma marcha, se converte em praça pública, e passa a narrar como até então pecara e agora descobrira a fé; seu exemplo é seguido por vários (YOUNG, 2002). O individual estava conectado ao coletivo, na forma da responsabilidade do indivíduo: é a sua imoralidade (seu racismo ou sua embriaguez) o que ameaça o bem comum. Assim, essas mobilizações de caráter religioso uniram, pela primeira vez, transformação pessoal e reforma política, de um modo bastante próximo aos movimentos políticos da década de 1960, mais preocupados com questões de identidade, estilo de vida e moralidade do que com uma questão econômica ou de política estatal.

Após a narrativa autobiográfica ter se tornado prática frequente e generalizada e após o uso dessa narrativa para mobilizações com fins seculares, o terceiro momento da história destaca a secularização da fé, ou melhor, de seus efeitos: a eleição torna-se autoestima e a força de vontade singular realiza o indivíduo nesse mundo. No século XIX, nos Estados Unidos, surgiu um conjunto de teorias preocupadas com o papel das crenças na produção de doenças, a chamada "mind cure" (cura da mente). Comum a essas teorias era a crença de que as doenças tinham origem e natureza psíquica, e por isso deveriam ser curadas mediante uma reordenação eficaz dos pensamentos do paciente. Esse movimento representou um encontro entre ideias medicinais e religiosas, constituindo uma forma inédita de espiritualidade.

Mais tarde, Norman Vincent Peale, pastor protestante americano, publicaria o best-seller de autoajuda The Power of Positive Thinking (1952). Nele, Peale 
defendeu que a fé religiosa poderia ser utilizada como instrumento para alcançar o sucesso na vida terrena. A atitude otimista daquele que crê em Deus provocaria mudanças positivas em seu estado mental que o levariam a ser vitorioso em seus objetivos (HEWITT, 1998, p. 44). Este nexo entre fé e recompensa na vida terrena também está na base da teologia da prosperidade: de maneira simples, a teologia da prosperidade é a crença de que Deus garante saúde e bem-estar, inclusive financeiro, àqueles que creem.

Os princípios da mind cure e do pensamento positivo constituíam aquilo que podemos chamar de uma "tecnologia espiritual", o uso da religiosidade para fins úteis (HOFSTADTER, 1963, p. 265). Para os seus adeptos, a relação estabelecida com Deus não deveria ser marcada pelo dever dos homens em buscar a retidão moral, mas pela possibilidade de ser feliz aqui e agora. A fé se desvinculou de uma relação com o pecado e com o castigo, se tornando apenas um meio para alcançar alguma gratificação nesta vida — e não mais a redenção após a morte. Ao invés de se conceber como um pecador indigno, o indivíduo era convocado a interiorizar uma imagem positiva de si. Este conjunto de crenças sobre o poder da fé e do pensamento positivo inaugurou o ethos da autoajuda, que mais tarde ecoaria na forma de discursos terapêuticos fundamentados na ideia de autoestima. A fé em Deus, antes, implicava simultaneamente uma crença na eleição do fiel e tinha como consequência dessa eleição a força de vontade acrescida, capaz de garantir sucesso no comportamento moral e nos negócios. Quando se torna tecnologia espiritual, a fé em Deus perde relevância; o foco passa a ser a "fé" em si mesmo, que já é suficiente para obter recompensas materiais.

O quarto elemento da história do testemunho de vítimas é o momento em que a cura pela narrativa autobiográfica se dá coletivamente, na forma da terapia em grupo. Em 1935, surge o Alcoólicos Anônimos: com seus 12 passos, o AA teve enorme impacto na cultura norte-americana, colocando-se como alternativa ao tratamento psiquiátrico e psicanalítico e vindo a se tornar fórmula de funcionamento para diversos outros grupos que lidam com vícios.

Embora o AA não se apresente como um grupo religioso, a estrutura do programa foi inspirada nas narrativas de conversão protestantes: em primeiro lugar, a experiência de desespero por se descobrir impotente diante de seus erros (o pecado ou o vício ou, ainda, a doença); em seguida, o contato com o testemunho de outros alcoólicos e a descoberta de uma força superior (o momento de conversão); finalmente, a conquista da sobriedade 
prometida pelo programa (a salvação pela graça). A dinâmica testemunhal é essencial ao programa dos 12 passos. Nas reuniões, cada membro deve se apresentar e afirmar ser um alcoólico: “Esta afirmação é o fundamento sobre o qual o direito de testemunhar está apoiado. O reconhecimento [de sua condição] confirma o desejo de deixar de beber, que é o único requerimento para se tornar um membro" (KURTZ, 1979, p. 215). Nesse testemunho, o alcoólico narra como sua vida foi interrompida pelo álcool: em que momento a bebida se tornou um vício, quais as consequências desse vício em sua vida, o momento de entrada no AA e as alegrias e dificuldades de manter-se sóbrio. A vontade de um poder superior ao indivíduo será suporte para a vontade humana na relação "saudável", moral, que ela necessita estabelecer com os impulsos do corpo. As aspas importam: os grupos de AA não estavam preocupados em questionar; queriam, sim, adequar os indivíduos às regras sociais.

\section{Década de 1960: a liberação do self e os novos movimentos políticos}

Trinta anos mais tarde, os movimentos libertários dos anos 1960, ao defenderem a generalização da exigência de autenticidade, promoveram uma inversão na relação entre indivíduo e sociedade nas terapias de grupo. A retórica terapêutica passa a ser pela liberação do self diante de uma sociedade opressiva. Basta pensar no surgimento do conceito de codependência: os codependentes eram indivíduos que apresentavam uma condição de dependência emocional, uma necessidade considerada patológica de obter aprovação e validação de terceiros que se desenvolveria como "resultado de uma exposição prolongada do indivíduo a um conjunto de regras opressivas - que não permite a expressão aberta dos sentimentos nem a discussão direta de problemas pessoais e interpessoais" (RICE, 1998, p. 9).

A cura dos codependentes demandava que eles reconquistassem a autoestima que havia sido negada na infância, recuperando sua autonomia. Para tanto, era preciso que eles localizassem a causa de seus sofrimentos no mundo exterior, em instituições como a família e o casamento. Se no Alcoólicos Anônimos o testemunho servia para o indivíduo narrar como o seu vício era causa de seu sofrimento (e portanto, assumir a responsabilidade e a obrigação de se manter sóbrio), no caso dos codependentes seus sofrimentos eram remetidos a ações opressivas de um terceiro. A partir de então, os indivíduos passaram a ser incitados a interpretar suas experiências 
e sofrimentos como resultantes da dificuldade de definir ou encontrar a sua verdadeira identidade em face da moralidade conservadora hegemônica. Enquanto acredita no olhar negativo do outro, o indivíduo estaria marcado pela baixa autoestima, por pensar mal sobre si.

Nessa prática, a fé está secularizada: de um lado a salvação é mundana; de outro, a variação da autoestima é constituída nos processos de socialização. As narrativas autobiográficas passam, então, a frisar as ocasiões nas quais os indivíduos foram vítimas de preconceito ou violência e o momento quando decidiram não mais ter vergonha, não mais temer as opiniões preconceituosas. Antes, nos testemunhos de graça, a fé era vista como modo de o indivíduo alcançar a salvação (divina ou mundana, religiosa ou secular); agora, é o aumento da autoestima que permitiria o indivíduo agir autonomamente, descolado das expectativas alheias que supostamente o limitariam.

Ao invés de reconhecerem que faziam vítimas com seu comportamento e procurar a reconciliação, como na narrativa dos membros do AA, os indivíduos se concebem como vítimas de violência e preconceito na luta por afirmar sua identidade (RICE, 1998). Ao contrário dos protestos religiosos do século $X I X$, nos quais era o pecado individual que poderia comprometer a felicidade coletiva, nos movimentos de vítima contemporâneos a imoralidade alheia é o que causa diversos sofrimentos a membros de um grupo que se concebe como estigmatizado. Neles, um sofredor se mobiliza contra essa imoralidade, assume e se orgulha da identidade que lhe fez ser vítima de preconceito, testemunha de seu sofrimento e, assim, conecta novamente o individual e o coletivo, o sofrimento e a imoralidade, promovendo a mobilização de vários.

O último elemento para completar o quadro histórico do testemunho nas cenas de cura e mobilização é dado pelas práticas dos movimentos feministas e dos grupos de veteranos do Vietnã nas décadas de 1960 e $70^{6}$. O movimento feminista, inicialmente apenas nas universidades, criou os grupos de consciousness raising por combinar o grupo de estudo com a ideia de que o pessoal é político (RAPPING, 1996; SARACHILD, 1975). A "tomada de consciência" não dependeria apenas do estudo de livros e artigos; dependeria também, e sobretudo, da narrativa de experiências pessoais. Pelo testemunho com detalhes da vida cotidiana, a opressão masculina se revela,

6 Em futuras pesquisas, seria importante também ressaltar, nesta história do testemunho, a relevância do movimento negro pelos direitos civis e sua relação com as igrejas protestantes. A título de exemplo, basta lembrar do papel fundamental do pastor batista e ativista político Martin Luther King Jr para este movimento nos EUA. 
esclarecendo para outras mulheres como a dominação se exerce, invisível, na vida cotidiana: “Os grupos de 'consciousness raising' foram um dos grandes sucessos do começo do movimento de liberação das mulheres. Foi um ótimo caminho para alcançar um grande número de mulheres e prover condições nas quais elas podiam desenvolver autoconfiança e a compreensão do que elas compartilhavam. Os grupos supriram uma necessidade e proliferaram" (PAYNE, 1973).

Já o movimento dos veteranos contrários à guerra se organizava desde o final dos anos 60 em Rap Groups, em que a mobilização dependia de cada um contar suas experiências na guerra (SCOTT, 1990). Além da finalidade política, o grupo também tinha uma função terapêutica, pois vários veteranos tinham restrições contra o serviço psiquiátrico oferecido.

Nem o movimento feminista, nem o movimento de veteranos do Vietnã precisaram inventar as reuniões de grupos onde se fala da vida privada; elas estavam dispersas na sociedade americana em diferentes práticas religiosas e terapêuticas, prontas para serem ressignificadas. A inovação consistiu em transformar essa forma discursiva em modo de mobilização. Adicionalmente, no AA, nos grupos de codependentes, nos Rap Groups e nos consciousness raising groups, a condição de participação é a experiência comum que define o grupo. Quem não passou pela experiência de alcoólico ou de vítima não pode participar, o que propicia um espaço seguro, sem julgamentos, que facilita o testemunho. A partir de então o testemunho se torna testemunho de vítima e se completa o movimento: embora a prática religiosa do testemunho de fé ainda permaneça no interior do protestantismo, outros movimentos se apropriam dessa prática e dão a ela um novo sentido.

\section{Testemunho de vítima e o sujeito da autoestima}

Dessa historicização, podemos derivar duas constatações cruciais: primeiro, a relativa autonomia de desenvolvimento de práticas terapêuticas e religiosas em países protestantes, especialmente nos Estados Unidos; segundo, que nenhuma transformação interna das práticas seculares derivadas do catolicismo produziria o testemunho como forma de terapia e mobilização política. Assim, nenhuma torção interna à dinâmica histórica da psicanálise conduziria ao testemunho em grupos de autoajuda, tendo em vista a centralidade do dispositivo de transferência para a prática psicanalítica. O sujeito da autoestima não pode ser, portanto, uma continuidade do sujeito de desejo, 
mas sim um desdobramento da história de uma outra espiritualidade, que desde o início esteve marcada por uma relação diferente com a regra.

Retornemos ao ponto de partida do quadro histórico: os testemunhos de vítimas de preconceito nos meios de comunicação. O testemunho é a voz da vítima, ou ainda, é a forma de o sofrimento ser expresso dada a ascensão do direito à liberdade individual. Claro que o testemunho de vítima como repertório de mobilização tem uma condição tecnológica: o surgimento da Internet e a "liberação do polo do emissor" (LEMOS, 2010). Mas também tem como condição esta longa história de como os indivíduos foram ao espaço público narrar suas vidas em busca da salvação pessoal e para converter novos seguidores.

Àquele que se concebe como vítima do preconceito alheio, são recomendados o aumento da autoestima e a recusa do questionamento: por um lado, pela valoração da autoridade da experiência, parece ser cada vez mais condenável que alguém que não faça parte do grupo estigmatizado questione a verdade contida no testemunho; por outro lado, pela valorização da autenticidade, questionar a si próprio passa a ser causa e sintoma da baixa autoestima. Essa revalorização da certeza - e não da distância, do constante desconforto em relação às suas crenças — está articulado a uma postura narcísica, temerosa da inquietude.

O indivíduo torna-se competente em marcar a origem social e histórica de crenças preconceituosas - quando se trata de questionar a crença dos outros. Em relação a suas próprias crenças, só parece caber a certeza, pois qualquer distância de si a si pode ser interpretada como ausência de confiança em si mesmo. Tendo como reserva ética o pensamento moderno, podemos pensar que esse indivíduo que denuncia incessantemente o preconceito alheio só repete a moralidade vigente. Ao mesmo tempo em que questiona as autoridades paternalistas, não se inquieta com a pertinência histórica de suas crenças.

Se somos seres históricos, não basta desvelar o preconceito nas crenças daqueles que pensam diferente de nós; nossas vidas bem podem ser singulares, mas enquanto não nos confrontarmos com a historicidade dos conceitos com os quais pensamos o justo, nossas narrativas autobiográficas continuarão a ser padronizadas. 
Paulo Vaz é professor do Programa de Pós-Graduação em Comunicação e Cultura da Universidade Federal do Rio de Janeiro. É pesquisador $1 \mathrm{~A}$ do CNPq e doutor em Comunicação pela UFRJ. O autor agradece ao CNPq pelo apoio ao projeto de pesquisa.

paulovaz.ufrj@gmail.com.

Nicole Sanchotene é doutoranda no Programa de PósGraduação em Comunicação e Cultura da Universidade Federal do Rio de Janeiro e mestre em Comunicação pela UFRJ.

freire.nicole@gmail.com.

Amanda Santos é doutoranda no Programa de PósGraduação em Comunicação e Cultura da Universidade Federal do Rio de Janeiro (PPGCOM-UFRJ) e mestre em Comunicação pela UFRJ.

amandassantos94@gmail.com.

Contribuições de cada autor: Paulo Vaz: supervisão do projeto de pesquisa; fundamentação teórica e metodologia; primeira e segunda redação. Nicole Sanchotene: primeira e segunda redação, revisão e edição. Amanda Santos: primeira e segunda redação, revisão e edição.

\section{Referências}

AGAMBEN, G. Remnants of Auschwitz: the witness and the archive. Nova York: Zone Books, 1999.

BEVERLEY, J. Testimonio, Subalternity, and Narrative Authority. In: CASTRO-KLAREN, S. A Companion to Latin-American Literature and Culture. Oxford: Oxford University Press, 2008.

BUTLER, J. Relatar a si mesmo: crítica da violência ética. Belo Horizonte: Autêntica, 2015.

CALDWELL, P. The Puritan Conversion Narrative: The Beginnings of American Expression. Cambridge: Cambridge University Press, 1983. 
CARUTH, C. Unclaimed experience. Yale French Studies, n. 79, 1991.

DELUMEAU, J. O pecado e o medo no Ocidente. Bauru: EDUSC, 2003.

FOUCAULT, M. Dits et écrits II (1970-1975). Paris: Gallimard, 1994.

História da sexualidade I: A vontade de saber. Rio de Janeiro: Graal, 1988.

. História da sexualidade II: O uso dos prazeres. Rio de Janeiro: Graal, 1984.

Microfísica do Poder. Rio de Janeiro: Edições Graal, 1979.

Os Anormais: Curso no Collège de France (1974-1975). São Paulo: Martins Fontes,

2001.

Wrongdoing, Truth Telling: The function of avowal in justice. Chicago/Londres:

The University of Chicago Press, 2014.

HEWITT, J. P. The Myth of Self-Esteem: finding happiness and solving problems in America. Nova York: St Martin's Press, 1998.

HINDMARSH, D. B. The Evangelical Conversion Narrative. Oxford: Oxford University Press, 2005.

HOFSTADTER, R. Anti-intellectualism in American Life. Nova York: Viking Books, 1963.

ILLOUZ, E. Oprah Winfrey and the Glamour of Misery: An Essay on Popular Culture. Nova York: Columbia University Press, 2003.

KURTZ, E. Not-God: A History of Alcoholic Anonymous. Minnesota: Hazelden Publishing, 1979.

LEMOS, A. Cibercultura: tecnologia e vida social na cultura contemporânea. Porto Alegre: Sulina, 2010.

MCLOUGHLIN, W. G. Revivals, Awakenings, and Reform. Chicago: The Chicago University Press, 1978.

MEHL, D. La télévision de l'intimité. Paris: Seuil, 1996.

PAYNE, C. W. Consciousness Raising: A Dead End. In: KOEDT, A.; LEVINE, E.; RAPONE, A. (orgs). Radical Feminism. Nova York: Quadrangle Books, 1973.

PEALE, N. V. The Power of Positive Thinking. Nova Jersey: Prentice Hall, 1952.

PLUMMER, K. Telling Sexual Stories: Power, Change, and Social Worlds. Londres: Routledge, 1995.

RADSTONE, S. Cultures of confession/cultures of testimony: turning the subject inside out. In Gill, J. Modern Confessional Writing. Londres: Routledge, 2006. 
RAPPING, E. The Culture of Recovery: Making Sense of the Self-help Movement in Women's Lives. Boston: Beacon Press, 1996.

RICE, J. S. A Disease of One's Own: Psychotherapy, Addiction, and the Emergence of Co-dependency. New Brunswick: Transaction Publishing, 1998.

SARACHILD, K. Consciousness raising: a radical weapon. Feminist Revolution. Nova York Redstockings, 1975.

SCOTT, W. J. PTSD in DSM-III: A Case in the Politics of Diagnosis and Disease. Social Problems, v. 37, n. 3, p. 299-310, 1990.

SELIGMANN-SILVA, M. Narrar o trauma - a questão dos testemunhos de catástrofes históricas. Revista de Psicologia Clínica. v. 20, n. 1, p. 65-82, 2008.

TENTLER, T. N. Sin and Confession on the Eve of the Reformation. Nova Jersey: Princeton University Press, 1977.

WUTHNOW, R. Sharing the Journey: Support Groups and America's new Quest for Community. Nova York: Simon \& Schuster, 1994.

YOUNG, M. P. Confessional Protest: The Religious Birth of U.S. National Social Movements. American Sociological Review, v. 67, n. 5, pp. 660-688, 2002.

Artigo recebido em 09/03/2021 e aprovado em 09/06/2021. 